\title{
Problems of differentiation between epilepsy and non-epileptic paroxysmal events in the first year of life
}

\author{
A Shuper, M Mimouni
}

\begin{abstract}
Twenty two babies under 1 year old were referred for evaluation of suspected epileptic seizures. Nine were found to have epilepsy. In the other 13 - all developing normally, aged up to 10 months - the spells were non-epileptic paroxysmal events (NEPE). They consisted of five patterns of movement: (1) eye blinking; (2) 'no' movements; (3) body posturing with head and arm jerks; (4) masturbation-like movements; and (5) myoclonic head flexion. The NEPE were present for a period of two weeks to seven months. Although some NEPE cannot be clinically differentiated from true epilepsy, in these infants at least four interictal EEGs were normal, the spells completely resolved after a relatively short period without antiepileptic treatment, and the infants continued to develop normally with no evidence of epilepsy during a follow up period of 28 to 38 months. This sample indicates that the frequency of NEPE in the first year of life may be high. Cautious clinical consideration, repeat EEGs and, when appropriate, a few weeks' observation are recommended. Awareness of these benign behavioural spells in this young age group is important, and parents can be reassured. Nevertheless, the spells may illustrate a 'foggy frontier' between NEPE and epilepsy. The lack of evidence for any other disease process in affected infants, as well as the disappearance of the NEPE without any intervention, indicates that a maturational process may be involved. (Arch Dis Child 1995; 73: 342-344)
\end{abstract}

Keywords: non-epileptic paroxysmal events, epilepsy, infancy.

Non-epileptic paroxysmal events (NEPE) are a common occurrence in children and have gained a fair amount of attention in paediatric and neurological journals, especially in relation to their differentiation from epileptic seizures. ${ }^{1-6}$ The spectrum of clinical presentations of NEPE is wide and its aetiologies vary. ${ }^{45}$ The differentiation between true seizures and NEPE is much more difficult during the first year of life than in older age groups. Generally, parents and child are referred to either a neurologist or a paediatric emergency room for evaluation. An electroencephalogram (EEG) and other studies, such as blood tests or neuroimaging, are performed.
Several techniques may be applied to obtain a correlation between the spell and the EEG recording at the time, and since the introduction of epilepsy monitoring units, more children are being admitted to these facilities for a better definition of the paroxysmal spells. ${ }^{127}$ The whole process is very exacting, in terms of both financial cost and parental stress and worry, and every effort should be made to reach a diagnosis on clinical grounds.

The aim of the present study was to evaluate prospectively the natural history of NEPE in the first year of life in babies in whom a suspicion of epilepsy was raised by the primary physician.

\section{Methods}

Between 1 January and 31 December 1991, 22 babies aged 1 to 12 months were referred to our paediatric neurology service for evaluation of a possible seizure disorder. Referrals were mainly from the paediatric emergency room, but also from paediatric wards and primary physicians. All the babies were examined as acute cases within several days of onset of the spells and before any treatment. After a detailed history was obtained, patients underwent a general physical and neurodevelopmental examination. A routine blood sample was drawn for complete blood count and for electrolyte, glucose, calcium, and liver function testing. An EEG was obtained. If episodes continued, the EEG was repeated after two weeks, or earlier when necessary, and if normal, a third EEG was obtained two weeks later. At least one sleep recording was performed in each baby. A contrast enhanced computed tomography (CT) scan of the brain was performed in all babies with proven epilepsy as well as in patients 10,12 , and 13 (tables 1 and 2).

In the infants with epilepsy, treatment was begun. The remainder were followed up at monthly intervals until the spells ceased and did not reappear for at least one month. A fourth EEG was obtained two months after disappearance of the spells. Thereafter clinical follow up was maintained.

\section{Results}

In eight of the 22 babies the first EEG showed either clear epileptic discharges or abnormal slowing. Their pertinent data are summarised in table 1 . In an additional baby (patient 9), who had repeated episodes of unusual upper extremity abduction and extension, the first 
Table 1 Data in infants with diagnosis of epilepsy

\begin{tabular}{|c|c|c|c|}
\hline $\begin{array}{l}\text { Case } \\
\text { No }\end{array}$ & $\begin{array}{l}\text { Age at } \\
\text { referral } \\
\text { (months) }\end{array}$ & Description of spells & EEG pattern \\
\hline $\begin{array}{l}1 \\
2 \\
3 \\
4\end{array}$ & $\begin{array}{l}5 \\
6 \\
8 \\
6\end{array}$ & $\begin{array}{l}\text { Infantile spasms } \\
\text { Classic sala'am attacks } \\
\text { Classic sala'am attacks } \\
\text { Infantile spasms } \\
\text { Classic sala'am attacks }\end{array}$ & $\begin{array}{l}\text { Hypsarrhythmia } \\
\text { Hypsarrhythmia } \\
\text { Hypsarrhythmia } \\
\text { Hypsarrhythmia }\end{array}$ \\
\hline 5 & 9 & $\begin{array}{l}\text { Focal seizures } \\
\text { Left sided focal seizures (head trauma } \\
\text { and focal bleeding) }\end{array}$ & Focal spikes \\
\hline 6 & 10 & $\begin{array}{l}\text { Left sided focal seizures involving arm } \\
\text { and face (intracranial ependymoma) }\end{array}$ & Focal spikes \\
\hline 7 & 6 & $\begin{array}{l}\text { Generalised seizures } \\
\text { Generalised tonic-clonic and myoclonic } \\
\text { seizures }\end{array}$ & Diffuse slowing (at presentation) \\
\hline 8 & 6 & Generalised seizures & Diffuse spikes \\
\hline 9 & 8 & $\begin{array}{l}\text { Benign myoclonic epilepsy } \\
\text { Repeated episodes of rapid arm and } \\
\text { head jerking }\end{array}$ & $\begin{array}{l}\text { Two normal records; } 3 \text { rd showed } \\
\text { spike waves }\end{array}$ \\
\hline
\end{tabular}

two EEGs were normal, but a third showed bursts of generalised spike waves, and benign myoclonic epilepsy in infancy was diagnosed. In these nine babies, antiepileptic treatment was begun and management continued according to the seizure disorder.

Thirteen babies were found to have repeated spells with normal interictal EEG recordings. All had been born at term after a normal pregnancy; two were delivered by caesarean section. Apgar scores were 9 or 10 in all cases. In none of these babies was there a family history of epilepsy. Initial physical and neurological examination was normal. In none was there any suspicion of a gastrointestinal problem. Developmental screening results were appropriate for age; routine blood tests and head CT showed no abnormalities. At least one typical spell of each baby was witnessed by a physician during the follow up period.

Table 2 Data in infants with non-epileptic paroxysmal events

\begin{tabular}{|c|c|c|c|}
\hline $\begin{array}{l}\text { Case } \\
\text { No }\end{array}$ & $\begin{array}{l}\text { Age at } \\
\text { referral } \\
\text { (months) }\end{array}$ & Description of spells & Duration \\
\hline 10 & 4 & $\begin{array}{l}\text { 'No' movements } \\
\text { Many episodes per day of side to side head } \\
\text { shaking, as if saying 'no' }\end{array}$ & 7 Months \\
\hline 11 & $6 \cdot 5$ & $\begin{array}{l}\text { 'No' movements for } 2 \text { months, similar to those in } \\
\text { patient } 3 \text {, which changed to repeated to and fro } \\
\text { movements of the upper body }\end{array}$ & $\begin{array}{l}\text { To and fro movements } \\
\text { continued for } 2 \\
\text { months }\end{array}$ \\
\hline 12 & 7 & Similar to patient 3 & 2 Months \\
\hline 13 & 2 & $\begin{array}{l}\text { Eye blinking } \\
\text { Many episodes per day of rapid eye blinking, about } \\
1 / \mathrm{s} \text {, lasting for several minutes }\end{array}$ & 2 Months \\
\hline 14 & 6 & $\begin{array}{l}\text { Head flexion } \\
\text { Repeated clusters of myoclonic head flexion in the } \\
\text { midst of all types of activity }\end{array}$ & 2 Months \\
\hline 15 & 10 & $\begin{array}{l}\text { Masturbation movements } \\
\text { Repeated episodes of whole body stretching and } \\
\text { rubbing against the bed, with rapid breathing } \\
\text { and sweating as if masturbating }\end{array}$ & 3 Months \\
\hline 16 & $5 \cdot 5$ & $\begin{array}{l}\text { Body posturing } \\
\text { Five periods of opisthotonic-like posturing and } \\
\text { staring }\end{array}$ & 3 Weeks \\
\hline 17 & 3 & $\begin{array}{l}\text { Repeated facial flushing, staring and flexion of all } \\
\text { extremities, associated with crying, of several } \\
\text { seconds' duration }\end{array}$ & 2 Weeks \\
\hline 18 & 4 & $\begin{array}{l}\text { Daily episodes of bluish discoloration of face and } \\
\text { bilateral arm abduction }\end{array}$ & 1 Month \\
\hline $\begin{array}{l}19 \\
20\end{array}$ & $\begin{array}{l}5 \\
8\end{array}$ & $\begin{array}{l}\text { Repeated myoclonic-like head jerks to the left } \\
\text { Repeated daily episodes of head turning and arm } \\
\text { stretching to the left }\end{array}$ & $\begin{array}{l}3 \text { Weeks } \\
1.5 \text { Months }\end{array}$ \\
\hline $\begin{array}{l}21 \\
22\end{array}$ & $\begin{array}{l}9 \\
9\end{array}$ & $\begin{array}{l}\text { Repeated episodes of arm stretching } \\
\text { Three discrete episodes of sharp screaming, body } \\
\text { stiffening and bluish discoloration of face for } \\
\text { several seconds }\end{array}$ & $\begin{array}{l}1 \text { Month } \\
3 \text { Weeks }\end{array}$ \\
\hline
\end{tabular}

Nevertheless, in only two cases had an attack been recorded on the EEG. The pertinent data with regard to the spells are summarised in table 2 .

The 13 babies with non-epileptic spells showed five types of movements:

(1) Repeated episodes of rapid eye blinking

(2) Repeated episodes of head shaking, as if saying 'no'

(3) Body posturing and stretching with head turning, arm stretching, and change in facial colour

(4) Masturbation-like activity

(5) Recurrent clusters of head flexion.

All the spells disappeared completely during the follow up period. Based on parental reports, the frequency of the spells gradually decreased in the period preceding their total cessation. The mean period through which the spells were present was eight weeks, with a range of two weeks to seven months. The complete disappearance of the spells was confirmed in all patients. None of the babies received anticonvulsant therapy. The mean follow up period after disappearance of the spells was 34 months (range 28 to 38 months). Of note is patient 11 in whom different spells appeared transiently. No developmental arrest or regression was noted during the follow up period. Neurological examination continued to be normal. In all of these 13 babies, the fourth EEG was also normal.

\section{Discussion}

Out of 22 babies under 1 year old who were referred for neurological evaluation because of suspected epilepsy, $13(59 \%)$ were presumed to have NEPE. They underwent repeated EEG recordings, all of which were normal, and their spells completely disappeared after a relatively short time without any antiepileptic treatment. Although interictal EEG recording has limited diagnostic usefulness, the yield of four recordings is considered to be above $90 \% .^{38}$ The absence of evidence of epilepsy during the follow up period also indicates the nonepileptic nature of the spells.

The infants who had NEPE had several characteristics in common: all presented during their first year of life with a repeated episodic pattern of movement which lasted for several weeks or months and then disappeared completely, with no accompanying abnormality in psychomotor development. It seems that NEPE in this age group are common - at least as common as epilepsy.

With regard to the NEPE in our patients, the 'no' movements and the masturbation-like movements could be presumed to be behavioural, comforting, and self stimulatory. In this regard, patient 11 is of interest because his 'no' movements later changed to whole body to and fro movements - clearly a behavioural pattern. The masturbation-like movements may well be considered behavioural rather than epileptic, although the latter possibility has been reported. 9 
On the other hand, the other types of movement are not easily differentiated from epileptic seizures. Especially in patient 14, the spells resembled what has been termed benign non-epileptic infantile spasms ${ }^{10}$ or benign myoclonus of early infancy. ${ }^{11}$ As in the descriptions in the latter studies, our patients were normal, no EEG abnormality was noted, and the phenomenon was self limited. Of note is the relatively short duration of the spells in patient 14, lasting for two months before completely disappearing.

With regard to benign myoclonic epilepsy in infancy, ${ }^{1011}$ this type of epilepsy also occurs in otherwise normal children. Although EEG tracings may be normal between myoclonic attacks they may show generalised spike waves occurring in brief bursts during the early stages of sleep. ${ }^{1213}$ Our patient 9 is a typical case, in whom only the third EEG was diagnostic. However, in this patient, the frequency and severity of the spells gradually increased until the appropriate diagnosis was reached. In the patients with suspected NEPE, the course of the spells was benign and relatively short.

The definite diagnosis of epileptic seizures must rest on the clinical presentation and evidence of seizure discharges on the EEG, performed during an acute event while using appropriately placed electrodes. The most accurate facility to help in establishing the diagnosis in questionable cases is an epilepsy monitoring unit. An ambulatory EEG recording may also be used. However, these tools are expensive and not always available. Retrospectively, the relatively short and benign course in the babies with NEPE did not justify the use of such facilities.

The list of paroxysmal events in children is long. ${ }^{3}$ Syncopal attacks, breath holding spells, sleep disturbances, psychologic disorders, migraine and its 'variants', and Sandifer's syndrome are commonly encountered. Several movement disorders mimicking epilepsy are also mentioned, such as paroxysmal choreoathetosis, dystonia musculorum deformans, and tic disorders, as well as much more frequent patterns like shuddering spells and jitteriness. ${ }^{3} 1415$

Similar problems in differentiating between true seizures and non-epileptic events also exist in the neonatal period. ${ }^{16}$ Our study shows that this difficulty extends well into the first year of life.

The appearance of NEPE at some stage of early development and its subsequent disappearance with no intervention after several weeks or months, with no other developmental abnormality, may indicate that it is in effect an anatomical or biochemical maturational phenomenon in the brain. Its physiology may only be assumed at present. The immature brain is considered to be susceptible to enhanced excitation and diminished inhibition. ${ }^{17}$ This may explain these spells, although proof is lacking. It may be further speculated that similar maturational mechanisms are responsible for benign myoclonus of early infancy as well. The similarity in the clinical presentation in some cases of NEPE and certain seizure disorders reflects the currently foggy frontier between these two entities.

We conclude that during the first year of life infants may present with a wide spectrum of movement patterns which mimic epilepsy. These spells may appear in normal infants and do not interfere with further normal development. They are also limited in duration. Their appropriate diagnosis should rest upon a thorough description, careful clinical judgment, and repeated examinations. If clinical indicators of cerebral malfunction, for example abnormal muscle tone or developmental delay, are present, they should also be taken into consideration. Thereafter, based on the data obtained, several weeks of clinical follow up are recommended. A significant number of these spells will resolve spontaneously. If there is no improvement, further studies are needed, including home EEG or video-EEG recording or admission to an epilepsy monitoring unit. Awareness of the benign nature of NEPE and its not infrequent occurrence can prevent the use of expensive diagnostic facilities as well as allay unnecessary fears in parents. Whether NEPE are benign maturational phenomena or an undiagnosed benign seizure disorder is as yet an unanswered question.

1 Desai P, Talwar D. Nonepileptic events in normal and neurologically handicapped children: a video-EEG study. Pediatr Neurol 1992; 8: 127-9.

2 Duchowny MS, Resnich TJ, Deray MJ, Alvarez LA. Video EEG diagnosis of repetitive behavior in early childhood and its relationship to seizures. Pediatr Neurol 1988; 4 $162-4$

3 Golden GS. Nonepileptic paroxysmal events in childhood. Pediatr Clin North Am 1992; 39: 715-25.

4 Murphy JV, Dehkharghani F. Diagnosis of childhood seizure disorders. Epilepsia 1994; 35 (suppl 2): S7-17.

5 Pedley TA. Differential diagnosis of episodic symptoms. Epilepsia 1983; 24 (suppl 1): S31-44.

6 Rothner $\mathrm{AD}$. Not everything that shakes is epilepsy: the differential diagnosis of paroxysmal nonepileptiform disorders. Cleve Clin $f$ Med 1989; 56 (suppl part 2): S206-13.

7 Holmes GL, Sackellares JC, McKierman J, Regland M, Dreifuss FE. Evaluation of childhood pseudoseizures using EEG telemetry and video tape monitoring. $\mathcal{F}$ Pediatr using EEG teleme

8 Salinsky M, Kanter R, Dasheiff RM. Effectiveness of multiple EEGs in supporting the diagnosis of epilepsy: an operational curve. Epilepsia 1987; 28: 331-4.

9 Livingston S, Berman W, Pauli LL. Masturbation simulating epilepsy. Clin Pediatr (Phila) 1975; 14: 232-4.

10 Dravet C, Giraud N, Bureau M, Rojer J. Benign myoclonus of infancy or benign non-epileptic infantile spasms. Neuropediatrics $1986 ; 17$ : 33-8.

11 Lombroso CT, Fejerman N. Benign myoclonus of early infancy. Ann Neurol 1977; 1: 138-43.

12 Dreifuss FE. Classification of epileptic seizures and the epilepsies. Pediatr Clin North Am 1989; 2: 265-79.

13 Dravet C, Bureau M. L'epilepsie myoclonique benigne du nourrisson. Rev EEG Neurophysiol 1981; 11: 438-44.

14 Holmes GL, Russman BS. Shuddering attacks: evaluation using electroencephalographic frequency modulation using electroencephalographic frequency modulation 1986; 140: $72-3$.

15 Shuper A, Zalzberg J, Mimouni M. Jitteriness beyond the neonatal period: a benign pattern of movement in infancy. f Child Neurol 1991; 6: 243-5.

16 Scher MS, Painter MJ. Controversies concerning neonatal seizures. Pediatr Clin North Am 1989; 36: 281-310. 17 Moshé SL. Seizures in the developing brain. Neurology 